\title{
Analysis of Economic Growth Trend under the background of Stagflation and Warning to Chinese Current Economic Situation
}

\author{
Chenning $\mathrm{Yu}^{1, \mathrm{a}}$, Yaojue $\mathrm{Xu}^{2, \mathrm{~b}}$ and Zhuoxiang Huo ${ }^{3, \mathrm{c}}$ \\ ${ }^{1}$ Kuang Yaming Honors School, Nanjing University, Nanjing 210000, China \\ ${ }^{2}$ Dornsife College of Letters, Arts and Sciences, University of Southern California, LA, CA90007, \\ USA \\ ${ }^{3}$ Department of Economics, University of Wisconsin-Madison, Madison, WI53703, USA

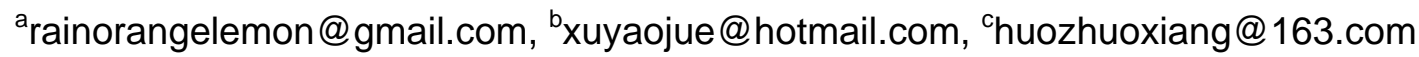

Keywords: Economy, Stagflation, Government policy, Inflation, Analysis

\begin{abstract}
With the trends of slow growth and inflation pressures manifesting in the economy, our society is showing potential signs of stagflation. For many years, our country has been living on investment and exports to stimulate economic growth, lacking endogenous spending power. Due to the effect of macroeconomic policies, there exists a time lag effect of economic spillovers of import trade in the short run. It is thus is necessary to analyze the problem of economic stagflation, and ensure that it is nipped in the bud. The phenomenon of stagflation in a macroeconomic sense means the concurrent economic phenomena of economic stagnation, high unemployment and high inflation. There are two factors that increase stagflation risks: (1) Improper economic policy, such as a central bank allowing excessive growth in the money supply, or government over-regulation in the commodity and the labor markets. (2) Economic capacity being reduced by a negative supply shock. With the recent strategic shift of the United States, several regional issues have been continuously fluctuating in the Asia-Pacific region. Therefore, the research topic of this paper is to determine which policies should be enacted by the Chinese government in order to ensure sustained and healthy economic and social development. In this paper, we comprehensively analyze the potential factors which cause economic stagflation, and we propose several corresponding suggestions in order to preempt potential manifestations of this phenomenon.
\end{abstract}

\section{Introduction}

The phenomenon of stagflation usually manifests in the form of economic stagnation, high inflation, a high unemployment rate and an economic recession. According to Keynsian Economics, the phenomenon of economic stagnation combined with mass unemployment can only exist in the crisis phase and depression stages of the economic cycle. At the same time, the phenomena of currency deflation and price falling will appear. On the contrary, in periods of economic development, the phenomenon of inflation and price rising will exist, however, there is no economic stagnation and mass unemployment at this stage[1].

With the sustainable development of the Chinese economy, there are always some economic risks. The possibility of economic stagflation is of particular concern. Once the phenomenon of stagflation appears, the sustained and healthy development of China's economy will cease, and stagflation will endanger social harmony and stability. Nevertheless, a slowdown in economic growth will first engender the problem of increasing employment pressure, which may widen the gap between the rich and the poor. In 2009, Li Bingyan, Liu Bianye[2] analyzed macroeconomic data; they conclude that the Chinese economy has been showing signs of stagflation, and that the government should reform their micro-economic policy. The phenomenon of economic stagflation in socialist countries is different from the stagflation crises that have occasionally appeared in western countries, because the socialist countries have their own special economic systems. The economic systems in socialist countries are generally some form of a commodity economy based on public ownership, whose basic contradiction is the unbalance between productivity and production relation. 
Specifically, the risk of stagflation in China is embodied by the following aspects: (1) Weakening of the export-led growth model; (2) Lack of technological innovation; (3) Disequilibrium of the international balance of payments, and deterioration of the international financial situation; (4) Lack of large-scale consumer demand; (5) Decline of industrial investment and marginal productivity of investment.

Regarding the aforementioned problems, in this paper we advance the following recommendations to improve China's economic model: (1) Promote technological innovation; (2) Stabilize the RMB exchange rate and strictly control capital inflows to limit speculative attacks on the currency; (3) Reform the separated operation system of bank payments; (4) Enhance real economic vitality and eliminate "zombie" enterprises; (5) Take drastic measures to control inflation; (6) Stimulate domestic demand and consumption; (7) Reform the current economic development model, and develop a circulating economy.

\section{The Causes and Manifestations of Stagflation}

In 1970, the phenomenon of stagflation appeared in several industrialized western countries. This took the form of simultaneous mass unemployment and serious inflation. The causes of stagflation have always been a matter of some debate. We believe that this phenomenon can be analyzed from the two angles of economic fundamentals and macroeconomic policy[3].

From an economic perspective, the causes of stagflation mainly have been negative supply shocks' effect on aggregate demand, declines in labor productivity and the rigidity of real wages[5].

\subsection{Three Stages of Stagflation in the United States between 1960 and 1980}

The United States economic stagnation started in 1960, during the Kennedy administration. It gradually gathered pace during Nixon's presidency, (1969-1972), and then continued to develop during the financial doldrums following the 1974 oil crisis. Finally, the stagflation crisis peaked in 1980. The formation of stagflation in the United States is the result of a synthesis of international and domestic factors[4].

Economists always focus on two main criteria. The first is the headline inflation rate, which contains all the things that people purchase. The second standard is the core inflation rate, which excludes food and energy.

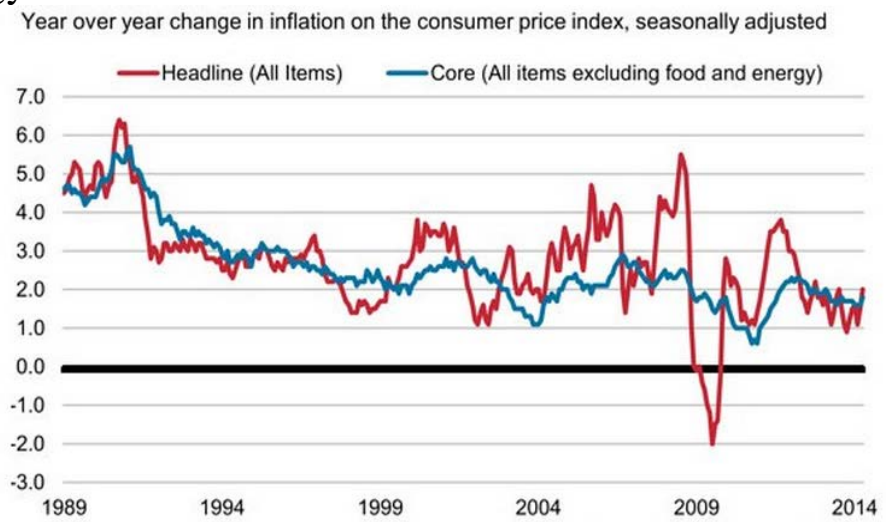

Fig. 1. Change in the headline inflation rate and core inflation rate in the US

From figure 1, we can determine that in the past 25 years, prices of all goods rose by $2.7 \%$ per year, and core prices rose by $2.6 \%$ per year.

\subsection{The Causes of Chinese Economic Stagflation}

Property rights are not clearly delineated in our country, and there exist a number of serious soft budget constraint problem in the process of budget management.

Most significantly, there is a lack of multi-level economic models, and there are too many monopoly elements. In Chinese economic model, primary sector industries cannot meet the needs of secondary sector industries, and the secondary sector industries cannot meet the needs of the service 
sector, and so on. As a result, the whole social economic structure presents a multi-level shortage. This means that in the case of no increase in supply, firms at all levels need to raise prices to increase profit growth, resulting in high commodity prices and leading eventually to stagflation.

From an economic perspective, the primary causes of stagflation in China are as follows:

(1) Declines in labor productivity and real wage rigidity;

(2) Failure to take the impact of demand into account;

(3) Negative aggregate supply shocks.

There are also several factors causing stagflation on the macroeconomic policy side:

(1) Price regulation has caused supply shortages, which leads to discrepancies between supply and demand.

(2) Currency fluctuations and inflation expectations are important causes of stagflation.

\subsection{The Phillips Curve Relationship and the Inflation-Money Growth Relationship}

In 1958, A.W. Phillips, a professor at the London School of Economics, examined the economic data in the UK between 1961 and 1957. He concluded that there is a stable inverse relationship between nominal wage growth rate and the unemployment rate, which is shown in figure 2 .

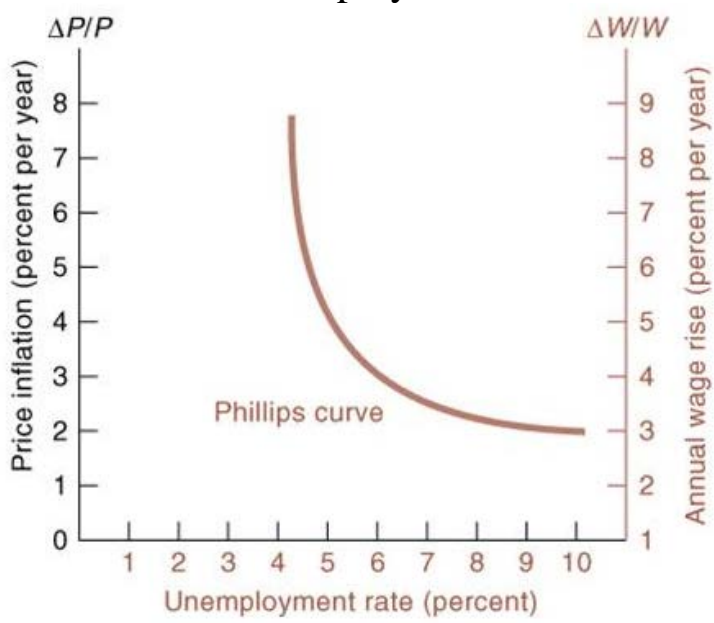

Fig. 2. The relationship price inflation, wage growth, and unemployment

After that, for different research purposes, economists transformed the original Phillips into two separate models: the "unemployment-price" curve and "growth-price" curve. The "growth-price" relationship curve was adapted to match Okun's law, as proposed by American economist Arthur Melvin Okun in 1962. The curve is shown in Fig.3.

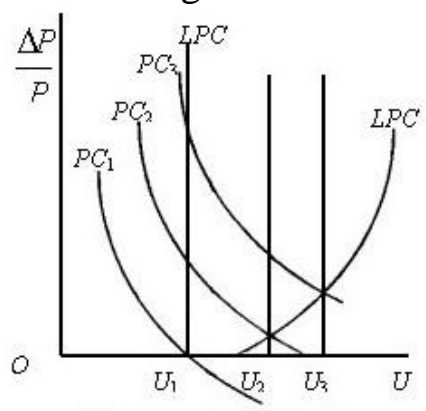

Fig. 3. "Growth-price" relationship curve

\section{Warning Signs in the Contemporary Chinese Economy}

According to the Phillips curve and its more sophisticated derivatives, there is an active relationship between growth and inflation. Precisely because of the complexity of this relationship between growth and inflation, it is neither practical nor desirable to control inflation by restraining growth. 
In terms of the causes of stagflation, we have determined that supply shocks and wage rigidity are related to economic fundamentals, while currency fluctuations, price controls, and inflation expectations are related to specific factors of economic policy. In terms of economic fundamentals, the probability of Chinese stagflation is very low. However, avoiding the future appearance of economic stagflation is an important issue for us.

In the following sections, we analyze the practical economic situation in our country, and create projections for quantitative economic growth potential and price trends in our country.

\subsection{Current GDP Growth Forecasts}

Figure 4 shows the GDP growth curve of China between 1978 and 2010. we can show that excluding the 1990's, the whole economic situation has remained remarkably stable since "Reform and Opening Up.”

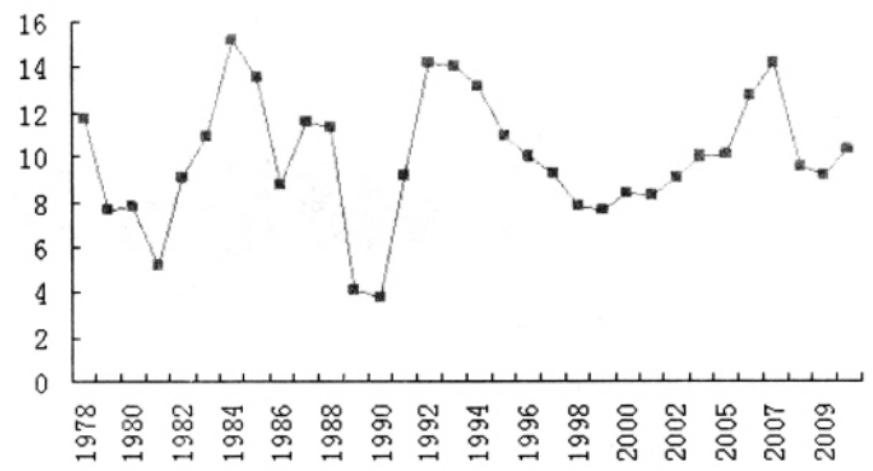

Fig. 4. GDP growth curve of China between 1978 and 2010

According to the method of unit root tests, the GDP growth rate is a stationary time series with the intercept term(1978-2010), thus we establish a GDP growth sequence equation:

$$
\begin{aligned}
& (G D P-10.02) \bullet\left(1-1.3 L+0.72 L^{2}\right)=(1+0.95 L) \xi_{t}\left(\begin{array}{l}
102.3 \\
0.00
\end{array}\right) \\
& \left(\begin{array}{c}
10.0 \\
0.00
\end{array}\right)\left(\begin{array}{l}
-5.6 \\
0.00
\end{array}\right)\left(\begin{array}{l}
-28.5 \\
0.00
\end{array}\right) \\
& R^{2}=0.59, D W=1.96, A I C=4.24, \operatorname{Pr} o b(F)=0.00
\end{aligned}
$$

According to the parameters of the equation, although the value of $R^{2}$ is small, other parameters' values are appropriate, and so the fitting effect of the equation is high.

\subsection{CPI Trend}

Inflation is always a monetary phenomenon. Before we evaluate the CPI trend, we must first analyze the lead-lag relationship of CPI and MI. Figure 5 is the monthly line graph of MI and CPI since 2001. In figure 5, we show that the MI and CPI trends are basically consistent in experiencing three rounds of inflation respectively. However, MI is has been consistently higher for the entire period.

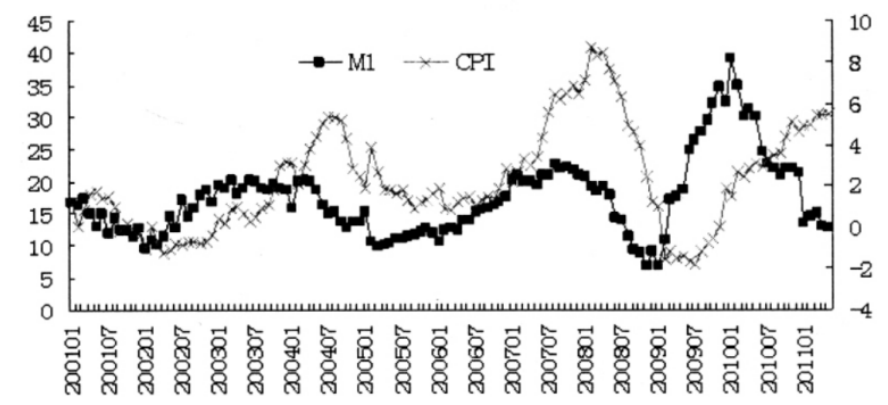

Fig. 5. MI and CPI trends

In the first round of inflation, the MI growth rate reached its lowest point in January 2002, and reached its peak in March 2003. In the second round of inflation, the MI growth rate reached its 
trough and peak in March 2005 and August 2007 respectively. In the third round of inflation, the MI growth rate reached its trough and peak in January 2009 and January 2010 respectively.

"Stagflation" is a historical phenomenon, and so it is also a historical process. At this stage, the economy of our country may thus soon see the phenomena of a declining growth rate and rising inflation. Nevertheless, the emergence of "stagflation" in the true sense is unlikely. Even so, we still have to analyze the trend of the economy, economic policies, etc. in order to avoid the problems described earlier in this paper.

\section{Potential Stagflation Factors in the Chinese Economy}

China is still in the primary stage of economic development. Despite the great progress that China's economic organizations have made over the last thirty years, China's economy is still well behind other emerging economies from the standpoint of GDP per capita. Although China is a big trading country, with a total export-import that dwarfs any other country, the proportion of net exports is still not high enough. Since 1991, net exports of goods and services as a percentage of GDP has never exceeded 9\%, which is less than the 15\% of GDP observed in Eastern European economies during their period of stagflation.

Although the phenomenon of stagflation is less likely to occur in our country, it doesn't mean that China's economic policymakers should not be alert to the following potential economic factors.

\subsection{High Inflation Rate}

A rise in inflationary pressures in China's economy is the biggest potential factor for stagflation. At present, China's inflation has been transformed from local, structural inflation to overall inflation, and inflation has reached a level that can't be relieved by squeezing companies' profits.

\subsection{Increasing Labor Costs}

With the increasing pace of China's economic development and urbanization, the dividend of cheap labor is gradually disappearing. Namely, rising labor costs will challenge China's original economic growth model. Our research results show that China has reached a Lewis turning point, and thus that an economic growth model which relies on cheap labor is will be unsustainable in the future.

\subsection{Unbalanced supply and demand structure}

China's domestic consumption is obviously insufficient. As a result, our economic growth model, which is heavily reliant on investment and exports, cannot be sustained.

\subsection{Volatile international situation}

Our country joined the World Trade Organization at the end of 2001. Since then, China's economy has been closely linked with the world economy. Since 2010, the international situation has become turbulent, especially with the unrest in the Middle East and overall worsening geopolitical risk. Those unstable international factors have pushed up prices for crude oil and other commodities, which has increased inflationary pressures in our country.

\section{Suggestions for the Reform of Economic Policy in our Country}

In order to curb inflation, promote economic growth and eliminate potential factors which may cause stagflation, the Chinese government should implement the following reforms.

\subsection{Increase Regulatory Control of Macroeconomic Policy}

It is of critical importance that the Chinese Government maintain price stability. In 2009, the four trillion yuan government investment plan was an important factor in increased inflation since 2010. Keynsian economists believe there is a division between effective demand and natural demand, and that expansion of fiscal policy and monetary policy will transform natural demand into effective demand, and so promote economic growth. However, several countries' experience has proved that loose policy will lead to the extreme expansion of credit, resulting in a serious increase 
of the headline inflation rate.

\subsection{Ensure differential policy}

While keeping tight control over fiscal and monetary policy, the government should implement differential policies. The central government should maintain social harmony and promote economic growth, paying close attention to the problem of financing for small and medium sized firms, and guide the flow of credit funds to diverse types of enterprises.

\subsection{Actively cultivate the domestic consumer market, and appropriately expand the scale of imports}

China's economy has made great achievements since the beginning for "Reform and Opening Up" in 1978, and living standards have been improving continuously. However, the investment and export led economic model is unsustainable in light of the limited natural resources of our country, which results in increasing inflation pressures in the domestic economy. China should appropriately increase the scale of imports, especially crude oil, coal, rice and other commodities.

\subsection{Adjust the industrial structure, look for a new "Economic Sweet Spot"}

"Workshop of the World" was a good reputation for our country to have. Nevertheless, China has basically stayed at the end of the industrial chain. Most industries in China are low technology, low value-added, high consumption, and highly polluting industries. China's human and natural resources insufficient to support the further development of this economic model. The government must therefore adjust the industrial structure and eliminate the most energy intensive enterprises, and mostly highly polluting. The government should also support technological innovation.

\section{Conclusion}

For many years, our country has been living on investment and exports to stimulate economic growth, lacking endogenous spending power. Because of the effect of macroeconomic policy, there exists a time lag effect of economic spillovers of import trade in the short run. Thus, it is necessary to analyze the problem of economic stagflation, and ensure that it is nipped in the bud. In this paper, we analyze the causes and manifestations of stagflation. Observing China's economic development, we single out the potential factors for stagflation and propose several suggestions to avoid their eventual manifestation.

According to the data analysis shown in this paper, we believe that stagflation may not appear in the foreseeable future. Although the phenomenon of stagflation is less likely to be caused in our country, it does not mean that China's economic policy makers can be complacent: we should be alert to the potential factors of economic stagflation and try our best to avoid them.

\section{References}

[1] Zhu, Yanning. Analysis and prevention of economic stagflation[J]. Journal of Shanxi Institute of Economic Management, 2014

[2] Li Bingyan, et al. nalysis of stagflation phenomenon of China's current economic operation[J]. China Journal of Economics, 2009

[3] Zhang, et al. The causes of stagflation and Chinese stagflation risk[J]. Journal of economic perspectives, 2011

[4] Knotek, Edward S. Regime Changes and Monetary Stagflation[J]. The Federal Reserve Bnak of Kansas City Economic Reserach Department, Research Working Paper, RWP, 2006

[5] Rogoff, Kenneth. Globalization and Global Disinflation[C]. The Federal Reserve Bank of Kansas City conference on "Monetary Policy and Uncertainty: Adapting to a Changing Economy", Jackson Hole, Wyoming: 2003 